\title{
A SIMULATION BASED DECISION SUPPORT APPROACH FOR OPERATIONAL CAPACITY PLANNING IN A CUSTOMER ORDER DRIVEN ASSEMBLY LINE
}

Michael Andersson

Department of Transportation and Logistics Chalmers

University of Technology

Affiliated to:

Department of Technology

University College of Gävle

80176 Gävle, SWEDEN

\section{ABSTRACT}

This paper reports on a project in the area of simulation based decision support (SBDS) at the operational level of the manufacturing system. The purpose of the project was to explore and describe the possibilities to use a standard discrete event simulation package for capacity planning purpose in a situation where labor was a primary and scarce production resource. This has been done through a case study at a Radio Base Station (RBS) assembly line at Ericsson Radio System, Gävle. Results from the study are a conceptual structure for a SBDS system and a prototype simulation system tailored for the RBS-2000 assembly line. The system has been tested in a simulated environment and results indicate a delivery precision improvement of eleven percent. Conclusions from the study are that this kind of tool for operational decision support offers a flexible decision support environment and that the need for high quality information and information collecting systems are crucial for the success of such tools.

\section{INTRODUCTION}

\subsection{Background}

The dynamics and flexibility of manufacturing systems are of increasing importance for companies in the global market. Two main strategies to gain competitive advantages are cost efficiency and superior value adding to customer (Christopher, 1992). To succeed in these strategies they must permeate all level of the company. At the operational level one important aspect of this process is the operational control of the manufacturing system. Typical activities in that process are short-term capacity and resource planning, scheduling and sequencing of customer orders. These activities are often characterized by a high degree of uncertainty both in needed input
Göte Olsson

\author{
Department of Technology \\ University College of Gävle \\ 80176 Gävle, SWEDEN
}

information and in actual execution of the control instructions by the manufacturing system.

\subsection{Problem}

Typically in a manual assembly line context the scarce production resource in the short term is labor (Lindau, 1995). This could be problematic for management of the production system. Absenteeism of labor due to illness, education, meetings etc., will affect the daily production capacity significantly. In a customer order driven production system the sensitivity will increase further. This is especially true when the time between point of order and point of delivery decreases. The traditional leveling buffers in the manufacturing system are eliminated in today's factories and the only possible way to cope with variations in demand is to construct the system with an inherited overcapacity. However, if two assembly lines with different products are run close to each other, there exists an opportunity to share labor between the two systems. This strategy will focus on cost efficiency in the way that when overcapacity exists in one system, resources could be redistributed to the other system. Such a design will, however, call for high quality information regarding current status of the two systems, and the available labor. Traditional methods to handle situations like this are based upon static priority rules, heuristics, and rules of thumb (Vollman, 1992). The problems with such methods are that they don't take the dynamics of the production system into account. Actually, there exists a strong relationship between the different components in the production system and action taken at one moment will affect the future status of the system. This indicates a need for more realistic tools for analysis of different decision alternatives. Research has shown that simulation can be a promising technique for this kind of problem (Jacksson, 1997). 


\section{Andersson and Olsson}

\subsection{Aim and Scope}

The aim of this study can be stated as:

To explore how discrete event simulation can be used in an operational decision situation regarding daily labor assignment in a customer-driven assembly line.

From this aim three objectives have been derived:

- To describe the role of discrete event simulation in manufacturing and how it can be used in operational decision situations.

- To develop a conceptual framework for the structure of a SBDS tool.

- To develop a prototype SBDS-system for the RBS 2000 assembly line.

The following statements define the scope of the study:

- The assembly system is studied in isolation from upstream and downstream systems. This simplification makes it possible to study the specific question and avoid including too much uncertainty and complexity into the simulation model.

- Discrete-event simulation will be used. The main reason for this choice is that the real logistics- and manufacturing systems under study all can be described in terms of states that change erratically in time, Harrell et.al., (1995). For example, a product enters the assembly line, an operation is finished, a customer order arrives etc. This implies that from now on when referring to simulation, this should be thought of as discrete-event simulation.

- The simulation model is used to forecast delivery precision and resource utilization on a day-to-day perspective under given circumstances.

- The user of the developed SBDS is assumed to be the supervisor of the workforce.

\section{EMERGENCE OF OPERATIONAL SIMULATION}

Schriber (1987) defines simulation as 'the modeling of a process or system in such a way that the model mimics the response of the actual system to events that take place over time'. Pegden et.al. (1995) define simulation as 'the process of designing a model of a real system and conducting experiments with this model for the purpose of understanding the behavior of the system and/or evaluating various strategies for the operation of the system'.

Historically simulation of manufacturing and logistics systems was concerned with strategic and tactical problems. Typically simulation was used to analyze why a disaster occurred in a production system or as a tool for testing a newly designed system before investing in it (Kelton, et.al 1998). Characteristic of these projects was that the simulation models used were of a "throw away" type. In the 1980s with the introduction of the personal computer, simulation software became easier to use. Commercial simulation software was developed and distributed and large corporations started to use the technique in a more extended way. It even became a formal requirement before approval of any capital investment. However it continued to serve as a tool for strategic and tactical decisions.

The real explosion in the area of simulation came in the middle of the 1990s. The reasons for this can be explained by: extended animation, ease of use, faster and cheaper computers, integration capabilities of the simulation packages to other software, and the evolution from general simulation languages to simulators. However, until now the most effort is still given to system design and system analysis.

One interesting area of simulation is the operational simulation (Savén, 1990). This concept covers short term planning and control of manufacturing and logistics systems by use of simulation models. This type of simulation presumes that simulation models are highly detailed and that they have a much longer lifetime than models from traditional simulation studies. Further they demand that the effort to update the model in accordance with the real system can be done in a time and cost effective way. With this type of model and with the integration possibilities to other information systems it is possible to run the simulation in real-time and in parallel with the real system. Further, by accelerating the simulation time analysts can look into the near future of the modeled system and hence test different decision alternatives.

The kinds of problems where operational simulation can be used are e.g. Scheduling, Capacity planning, Transport logic decisions, and FMS control. Jacksson et al. (1997), Czarnecki et al. (1997), Drake et al. (1996), Savén (1990). According to Banks (1997) these types of simulation are still in their infancy, but show great promise for the future. 


\section{A Simulation Based Decision Support Approach for Operational Capacity Planning}

\section{THE ASSEMBLY SYSTEM}

The assembly system studied consists of a PLC controlled line with one Climate assembly station, fourteen main assembly stations, which operate in parallel, six test stations, one repair station, one final control station and a scanning station for product traceabillity purpose. The workforce consists of two shifts working eight hours each. The dispatching to the assembly line follows the actual customer order inflow and is communicated to the assembly line supervisor daily through a production schedule. The maximum number of products in the assembly process has not been fixed. Because of confidential reasons no information about operation times are presented in the paper. The day-to-day capacity of the assembly line will vary because of absenteeism in labor. Hence, the supervisor of the shift will face a decision situation every morning as to whether people should be rescheduled from other assembly lines in the same facility.

\section{THE SIMULATION BASED DECISION TOOL DEVELOPMENT}

The development of the SBDS followed the general methodology for simulation studies drawn by e.g. Kelton $e t$ al. (1991) with some adjustment to the specific situation. The steps are listed in brief below:

- Formulation of problem and planning of the study

- Data collection and conceptual model development

- Validation of data and conceptual model

- Interpretation of conceptual model to simulation model

- Validation of simulation model

- Development of interfaces to other systems

- Validation of final SBDS tool

- Implementation of the SBDS tool at supervisor's computer

\subsection{Data Collection and Conceptual Model Development}

The data used in the model were collected from interviews with supervisors and assembly operators, and from documents. The main source was an external time study. This study was used to fill the model with mean operation times. Additionally a new time study was performed with the purpose of understanding how the manual assembly line coordination affected the flow time of the overall assembly system. It was also used to decide upon the distribution of the operation times.

The following models describe the assembly system:

- A Conceptual layout of the assembly line (not shown)

- A Logical model as a flowchart of the assembly process (Figure 1).
Figure 1: Logic of the Assembly Process

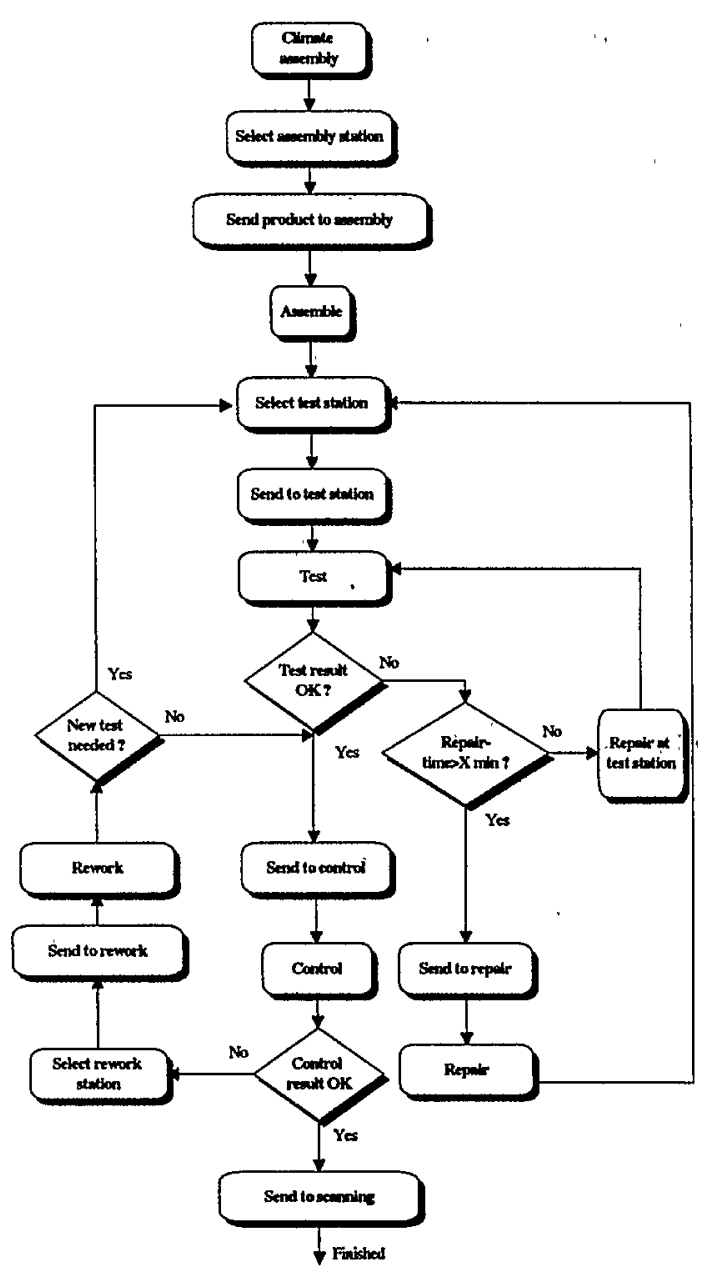

\subsection{Validation of Data and Conceptual Model}

The data from the external time study was already accepted as valid from production technicians and was in use for other purposes at the company. Data collected from other sources like interviews were checked with people familiar with the specific process. This was the case with e.g. scanning and climate assembly times. The conceptual model was also checked with people knowledgeable in the production and the technical aspects of the assembly line operation. This resulted in a few modifications. 


\subsection{Interpretation of Conceptual Model to Simulation Model}

A simulation model was built, based upon the information collected in the interviews and time data collections (Figure 2). It was developed in the simulation package Taylor II for Windows (F\&H Simulations Inc.), and consisted of 100 elements and 10 subroutines. The response variables of consideration were delivery precision of separate production orders and utilization of labor and operation stations. The input data to the model was suggested assignment of assembly, test and control personnel, divided upon the two shifts. Further the current delivery/production plan and the real time status of the assembly line was imported to the model in the beginning of every simulation run.

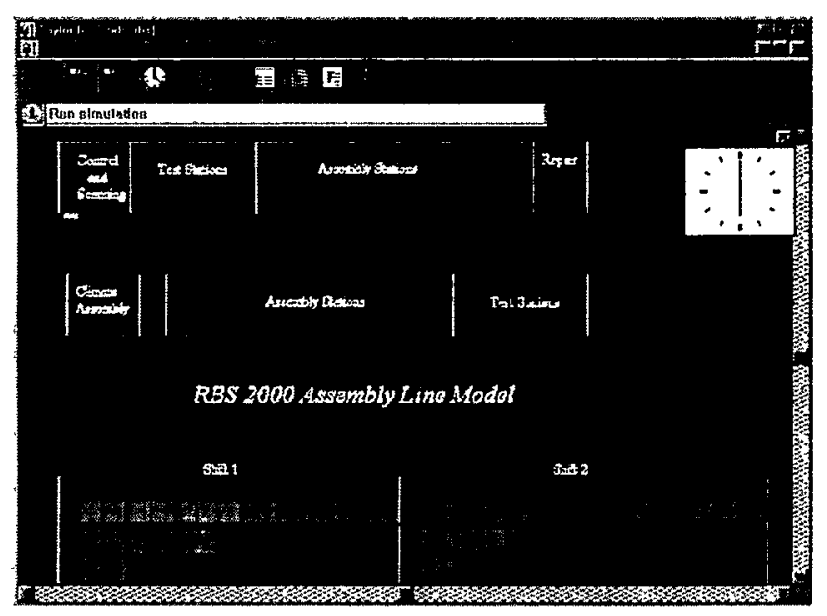

Figure 2: Screen-shot from the Simulation Model

\subsection{Validation of Simulation Model}

The simulation model was verified against the logical flowchart by help of Taylor's tracing tool. Further test runs were accomplished with one product at a time. Animation was used to eyeball the behavior of the simulated system and was found in accordance with specification.

The purpose of this study was not to come up with a working system but rather to explore the possibilities of using a commercial simulation package like Taylor II as a component in an operational decision support system. Thus, the throughout validation of the simulation models output related to the real assembly line has not been given first priority.

\subsection{Development of Interfaces to Other Systems}

Three systems where identified as interacting with the SBDS, they were:

- The human system (Decision-maker)

- The Manufacturing, Planning and Control System (MPCS)

- The Physical Assembly Line System

The simulation package Taylor II offers little user-friendly interface to the decision-maker. Hence a graphical user interface was developed in MS Excel for this purpose. By the use of dynamic data exchange (DDE) the communication between Taylor and Excel was accomplished. This method facilitated the possibility to run Excel macros, which in turn launched instructions to the simulation software. In the same way Taylor II used DDEfunctions to report simulation results into the Excel workbook.

From the MPCS input was needed regarding the current production plan. In the planning process the company used MS Office. It was then a natural step to use Excel as the bridge for all data communication.

The status of the physical assembly line system (presence of parts in the different stations and the time they have been there) must also be communicated to the simulation model. In the initial moment this data was kept by a PLC system which controlled the line. The only way to reach the data was through a local PC at the assembly line. However the SBDS was not supposed to be run on that computer but on the supervisor's PC. To solve this problem an Excel spreadsheet with links to the PLC program was placed on the $\mathrm{PC}$ at the assembly line. Then Microsoft NetDDE was used to reach this spreadsheet via external references from the supervisor's PC.

\subsection{Graphical User Interface}

The Graphical User Interface (GUI), was built in the MS Excel environment. This choice will facilitate exchange between the chosen simulation software, Taylor II, and other systems as well. One important aspect of the GUI was that it should be very easy to understand for the supervisor. This resulted in a final version shown in Figure 3. 


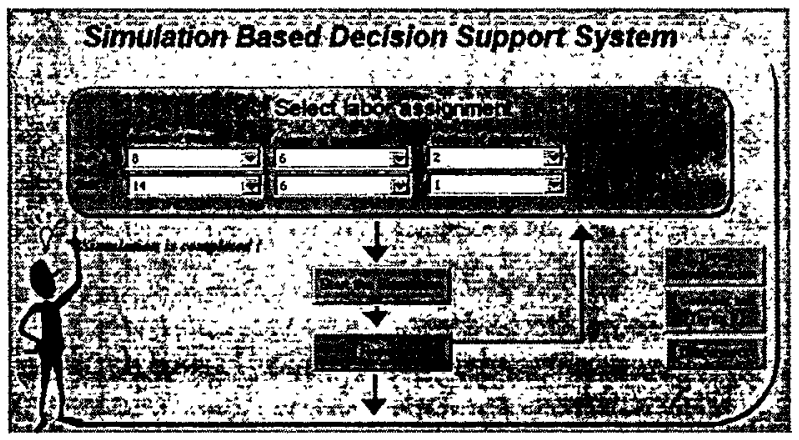

Figure 3: Graphical User Interface

The main idea is that the user will not need to know anything about the simulation software at all. Window scroll bars and buttons control everything. The decisionmaker just selects a number of available persons for assembly, test, and control. Further, by clicking the start button automatically the day will be simulated with current delivery plan and system status. After the simulation run the little "enlightened" man tells that the simulation is ready. Reports in shapes of tables and graphs are automatically generated and presented to the decisionmaker.

\section{THE RESCHEDULING EXPERIMENT}

To explore the value of the SBDS, it has been tested in a simulated environment for eight weeks. The scope of the study has concerned only one of the two assembly lines at the facility. To make it possible to evaluate the potential of the tool it was assumed that the parallel line was identical to the one modeled. This is a restriction in validity but the principle question whether the tool could support the decision-maker in the effort to maximize delivery precision will not suffer from this simplification. The two lines were simulated on a day to day basis. Five replications of each day were simulated and the decision-maker noted the average of the response variables: Labor utilization, and Delivery precision for the two lines. If the delivery precision fell below 100 percent the decision-maker took actions in accordance with the following rules:

1. If the parallel line performed well, i.e. 100 percent in delivery precision, consider borrowing labor.

2. Reschedule labor but never more than the overcapacity line will have a calculated labor utilization of 65 percent.

3. Simulate the day with the rescheduled staff.

4. If results are not satisfying iterate and fine tune from step 2.

5. Establish the new labor schedule.
The input data to the two simulation models were: Daily production volume DU(4,24), Available number of fitters $\mathrm{DU}(5,14)$, and Available number of testers $\mathrm{DU}(4,6)$.

\section{RESULTS}

The results from the experiment indicate that there exists an opportunity to improve delivery precision performance without increasing the total amount of resources when using the SBDS in combination with the decision structure described. Figure 4 shows the simulated delivery-precision for the eight weeks before and after the rescheduling procedure.

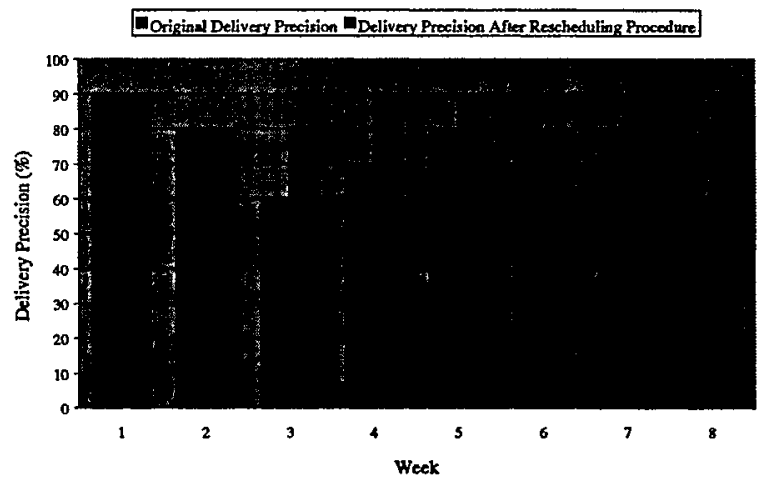

Figure 4: Results from the Rescheduling Experiment

The average delivery-precision during the eight weeks improved from $73 \%$ to $84 \%$ using the same staff but redistributed. The reason why there are no improvement in week one, two and six are due to the fact that both lines were exposed for contemporaneous peak demand.

The work with this case has furthermore resulted in the conceptual structure of a Simulation Based Decision Support System shown in Figure 5. This framework represents a flexible system with the advantage of the standard MS Office software for PC's. The flexibility is achieved through the modeling features in the easy to use simulation software Taylor II.

The structure in Figure 5 could be described as follows: The decision-maker has a set of decision alternatives. He communicates these to the simulation model via a graphical user interface. The current status of the studied system is further reported to the simulation model via the same interface and then the simulation model starts to run. After the experiment the results are reported back to the interface and are communicated to the decisionmaker, who takes a decision and executes it. 
Andersson and Olsson

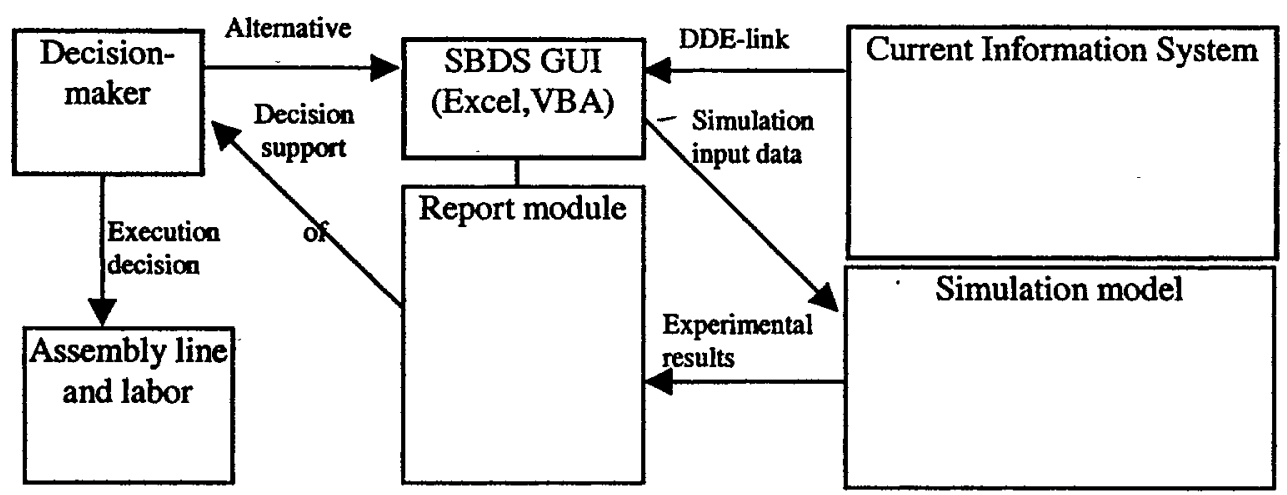

Figure 5: Conceptual Framework of a Simulation Based Decision Support System

The structure in Figure 5 could be described as follows: The decision-maker has a set of decision alternatives. He communicates these to the simulation model via a graphical user interface. The current status of the studied system is further reported to the simulation model via the same interface and then the simulation model starts to run. After the experiment the results are reported back to the interface and are communicated to the decisionmaker, who takes a decision and executes it.

\section{DISCUSSION AND CONCLUSIONS}

It is evident that this kind of decision support is promising. However, what has been clear during this study is the need for data access to the simulation model. In traditional simulation a time-consuming data collecting process can be permitted and included in the project's time schedule. However, in an operational simulation, data must be accessible in real time at the moment the simulation starts. In this particular case this was plain from the problem with initiating the simulation model with the real status of the assembly line every morning. If it is to be practically possible to use this kind of tool this initiation must be automated. At this moment such data wasn't kept by the assembly line information system. This implied that someone had to walk out to the line and by visual inspection write down this information and later edit it into the simulation model.

The problem with accurate and timely input data is probably one of the most critical aspects of operational simulation. Even if a functional data collecting system exists the sensitivity and vulnerability of such systems are high. This is especially true for systems including a high degree of manual involvement.

The conclusions drawn from this study are the following:

- It is technically and economically possible to develop simulation based decision support tools built upon standard simulators like Taylor II and standard spreadsheets like Excel.

- The combination of standard spreadsheet software and a standard simulation package offers a flexible decision support environment for evaluation of decision alternatives in a labor-rescheduling situation.

- To have practical use of such systems reliable information systems must exist and allow communication with the SBDS.

\section{ACKNOWLEDGEMENT}

This project was supported and financed by Ericsson Radio Systems $A B$ and the national research foundations distributed to the University College of Gävle.

\section{REFERENCES}

Banks, J. 1997. The Future of Simulation Software: A Panel Discussion, Proceedings of the 1997 Winter Simulation Conference, Ed. S. Andradóttir, K. J. Healy, D. H. Withers, and B. L. Nelson, Atlanta, GA, December, 166-173. IEEE, Piscataway, New Jersey.

Christopher, M. 1992. Logistics and Supply Chain Management Strategies for Reducing Costs and Improving Services, Pitman Publishing, London.

Czarnecki, H., M. M. Rahman, and B. J., Schroer. 1997. Using Simulation to Schedule Manufacturing Resources, Proceedings of the 1997 Winter Simulation Conference, Ed. S. Andradóttir, K. J. Healy, D. H. Withers, and B. L. Nelson, Atlanta, GA, December, 750-757. IEEE, Piscataway, New Jersey.

Drake, G., and J. Smith. 1996. Simulation System for Realtime Planning, Scheduling and Control, Proceedings of the 1996 Winter Simulation Conference, Ed. Charnes, J. M., Morrice, D. M., Brunner, D. T., and 
J.J., Swain, San Diego, CA, December, 1083-1090. IEEE, Piscataway, New Jersey.

Harrell, C., and K. Tumay. 1995. Simulation made easy, $A$ manager's guide, Industrial Engineering and Management Press, Institute of Industrial Engineers, Norcross, Georgia.

Jacksson, M., and C. Johansson. 1997. Real Time Discrete Event Simulation of a PCB Production System for Operational Support, Proceedings of the 1997 Winter Simulation Conference, Ed. S. Andradóttir, K. J. Healy, D. H. Withers, and B. L. Nelson, Atlanta, GA, December, 832-837. IEEE, Piscataway, New Jersey.

Kelton, W. D., and A. M. Law. 1991. Simulation Modeling and Analysis, $2^{\text {nd }}$ ed., McGraw-Hill International Editions.

Kelton, W. D., D. A. Sadowski, and R. P. Sadowski. 1998. Simulation with ARENA, WCB/McGraw-Hill.

Lindau, R. A. 1995. The impact of high-quality information on performance in manufacturing. Report 28, Department of Transportation and Logistics, Chalmers University of Technology.

Pegden, C., R. Sadowski, and R. Shannon. 1995. Introduction to Simulation Using SIMAN, $2^{\text {nd }}$ ed., McGraw-Hill, Singapore.

Savén, B. 1990. Produktions simulering. Mekanförbundets förlag, Uppsala.

Schriber, T.J. 1987. The Nature and Role of Simulation in the Design of Manufacturing Systems, Simulation in CIM and Artificial Intelligence Techniques, Ed. Retti, J., and K. E. Wichmann, Society of Computer Simulation, 5-18.

Vollmann, T. E., W. L. Berry, and D. C. Whybark. 1992. Manufacturing Planning and Control Systems, $3^{\text {rd }}$ ed., IRWIN.

\section{AUTHOR BIOGRAPHIES}

MICHAEL ANDERSSON is a Ph.D. student in the Department of Transportation and Logistics at Chalmers University of Technology. His area of research is modeling and analysis of logistics and manufacturing systems. He holds a B.S. in Industrial Engineering from the University College of Gävle.

GÖTE OLSSON was a Professor in Transportation and Logistics at Lund University from 1983 to 1991 . He is now active at the University College of Gävle. He is also an active consultant in the Swedish industry. His research interest includes simulation of manufacturing systems and warehouse systems. 